\title{
Valorisation of Coffee Roasting By-Products: Recovery of Silverskin Fat By Supercritical $\mathrm{CO}_{2}$ Extraction
}

\author{
Rita Nasti ${ }^{1}$ - Andrea Galeazzi ${ }^{3} \cdot$ Stefania Marzorati $^{1} \cdot$ Federica Zaccheria $^{2} \cdot$ Nicoletta Ravasio $^{2}$. \\ Giulia Luisa Bozzano ${ }^{3}$. Flavio Manenti ${ }^{3} \cdot$ Luisella Verotta $^{1}$
}

Received: 5 January 2021 / Accepted: 29 March 2021 / Published online: 9 April 2021

(c) The Author(s) 2021

\begin{abstract}
Recovery of agro and food-industrial waste and their valorisation via green technologies can help to outline new concepts of industrial strategies. In this contest, a fat enriched of added-value components was extracted from coffee silverskin by applying a supercritical fluid extraction technique $\left(\mathrm{sc}-\mathrm{CO}_{2}\right)$. An appropriate modulation of process parameters like temperature $\left(\mathrm{T}=35,50,60^{\circ} \mathrm{C}\right)$ and pressure $(\mathrm{p}=200-300 \mathrm{bar})$ influences the fat yield and the chemical composition, opening the way for targeted extraction. The extraction time, the organic solvent use and the energy consume were reduced compared to Soxhlet. Moreover, a mathematical model was constructed based on the experimental data collected, employed apparatus, and physico-chemical characteristics of biomass, pointing to a possible industrial scale-up. The experimental results are accompanied by a preliminary cost of manufacturing (COM), highlighting how the high investment for the apparatus is compensated by several benefits.
\end{abstract}

\section{Graphic Abstract}
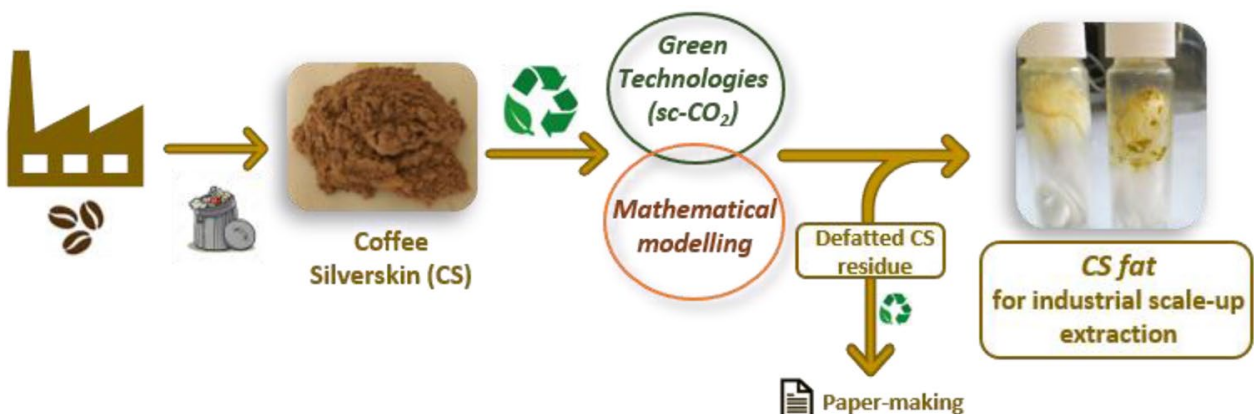

Paper-making

Keywords Coffee silverskin $\cdot \mathrm{CO}_{2}$ supercritical fluid $\cdot$ Fat $\cdot$ Fatty acids $\cdot$ Circular chemistry $\cdot$ Mathematical modelling

Rita Nast

rita.nasti@unimi.it

Andrea Galeazzi

andrea.galeazzi@polimi.it

1 Dipartimento di Scienze e Politiche Ambientali, Università Degli Studi Di Milano, Via Celoria 2, 20133 Milano, Italy

2 CNR SCITEC “G. Natta”, Via Golgi 19, 20133 Milano, Italy

3 Dipartimento di Chimica, Materiali e Ingegneria Chimica "Giulio Natta", Politecnico di Milano, Piazza L. Da Vinci 32, 20133 Milano, Italy

\section{Abbreviations}

A Model parameter of fast extraction period

$A A R D$ Average absolute relative deviation

$B \quad$ Model parameter of slow extraction period

$a_{0} \quad$ Specific interfacial area $\left(\mathrm{m}^{-1}\right)$

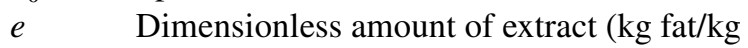
solute-free solid )

$\varepsilon \quad$ Void fraction in seed

$h \quad$ Axial coordinate (m)

$H \quad$ Bed height (m)

$J(x, y) \quad$ Interfacial mass transfer rate $\left(\mathrm{kg}\right.$ of fat $\left./ \mathrm{m}^{3} \mathrm{~s}\right)$

$k_{f} \quad$ Fluid phase mass transfer coefficient $\left(\mathrm{s}^{-1}\right)$ 


\begin{tabular}{|c|c|}
\hline$k_{s}$ & Solid phase mass transfer coefficient $\left(\mathrm{s}^{-1}\right)$ \\
\hline $\mathrm{m} 0 \mathrm{~s}$ & Initial solid mass ( $\mathrm{g}$ ) \\
\hline$P$ & Extraction pressure (bar) \\
\hline$Q$ & Flow rate $\left(\mathrm{m}^{3} / \mathrm{s}\right)$ \\
\hline$q$ & Dimensionless amount of $\mathrm{CO}_{2}$ \\
\hline$q_{m}$ & $\begin{array}{l}\text { Amount of } \mathrm{CO}_{2} \text { required in } \mathrm{CER} \text { period ( } \mathrm{kg} \text { of } \\
\mathrm{CO}_{2} / \mathrm{kg} \text { solute-free solid) }\end{array}$ \\
\hline$\rho_{s}$ & Solid mass density $\left(\mathrm{kg} / \mathrm{m}^{3}\right)$ \\
\hline$\rho_{f}$ & Fluid mass density $\left(\mathrm{kg} / \mathrm{m}^{3}\right)$ \\
\hline$S$ & Standard error of the estimate \\
\hline$t$ & Extracting time (s) \\
\hline$T$ & Extraction temperature $\left({ }^{\circ} \mathrm{C}\right)$ \\
\hline$U$ & Superficial velocity $(\mathrm{m} / \mathrm{s})$ \\
\hline$x$ & $\begin{array}{l}\text { Dimensionless concentration of solute in solid } \\
\text { phase }\end{array}$ \\
\hline$x_{0}$ & $\begin{array}{l}\text { Initial fat content of seed ( } \mathrm{kg} \text { fat } / \mathrm{kg} \text { solute-free } \\
\text { solid) }\end{array}$ \\
\hline$x_{k}$ & $\begin{array}{l}\text { Initial fat concentration inside the particles }(\mathrm{kg} \\
\text { fat } / \mathrm{kg} \text { solute-free solid) }\end{array}$ \\
\hline$y$ & $\begin{array}{l}\text { Dimensionless concentration of solute in solvent } \\
\text { phase }\end{array}$ \\
\hline$y_{r}$ & $\begin{array}{l}\text { Solubility of the solute in the solvent phase }(\mathrm{kg} \\
\left.\text { fat } / \mathrm{kg} \mathrm{CO}_{2}\right)\end{array}$ \\
\hline
\end{tabular}

\section{Statement of Novelty}

An enriched fat from silverskin, the unique coffee roasting by-product was extracted for the first time by supercritical carbon dioxide with main advantages respect the conventional approach.

\section{Introduction}

Within the context of circular economy, a fresh sustainable paradigm has increasingly been followed in many fields, from academia to industries and policymakers. Academic researchers are addressing their attention around this topic in the last decades, while companies are realizing the economic impact on themselves and their relative stakeholders [1].

The valorization of agro- and food-industrial waste is considered an opportunity to provide new higher-value products with a concomitant solution to waste accumulation issues. Different valorization strategies (pigments extractions, enzymatic bio-transformations, biofuels production, etc.) have been applied to different matrices always with the aim of creating added value from by-products $[2,3]$. In this wide context, many research groups are recently studying the valorisation of coffee by-products, since coffee is one of the most valuable primary products in the world trade and its processing chain leaves behind non negligible volumes of wastes [4]. After an initial process removing the outer skin, pulp, pectic adhesive layer and parchment, green coffee beans are exported to consuming countries where the beans are roasted and silverskin, the thin layer directly in contact with the coffee bean, is left over as the only by-product during the roasting step [5]. On the basis of data provided by coffee roasting companies, every 120 tons of roasted coffee, about one ton of silverskin is produced, and approximately 7500 tons per year in Italy (2017 data), representing a disposal problem in terms of environment and cost. Silverskin has already been investigated as combustible, fertilizer and animal feed [6], but many works pointed out the relevance of its phytochemical profile dealing with its antioxidant and prebiotic properties $[7,8]$.

In this framework, the Circular Coffee project (CirCo project-http://progettocirco.it/) aims at establishing a totally waste-free process as the different components of silverskin are valorized and converted to different uses. Coffee silverskin becomes an economic opportunity, as source of valuable compounds like: (i) fatty portion and bioactives, such as caffeine and caffeoylquinic acids [9] for cosmetic applications, (ii) the residual cellulosic part, for paper production. The partners in the project have already demonstrated the possibility to produce a lipstick prototype (Pirovano et al. 2019) from the lipidic fraction and, according to a patented procedure, the residual delipidated biomass was used in a paper making process (https://www.favini.com/en/news/ from-bean-to-crush-coffee/).

For the first purpose, the traditional extraction techniques already applied to silverskin aiming at obtaining extracts enriched with bioactive compounds, requiring high amounts of solvents, are not more acceptable if the background of green chemistry is becoming relevant in industrial sector. For this reason, recently, there has been an increasing demand for innovative and environmentally friendly extraction techniques in accordance with the agenda 2030 for sustainable development of United Nations.

In response to this issue, in this work, a green technique, employing supercritical $\mathrm{CO}_{2}\left(\mathrm{sc}-\mathrm{CO}_{2}\right)$, has been selected as the extraction strategy, being selective and able to reduce extraction time, avoiding or at least minimizing organic solvent consumption.

The most significant advantages of the supercritical $\mathrm{CO}_{2}$ extraction technique are $\mathrm{CO}_{2}$ cleanness and safety (carbon dioxide is non-toxic and non-inflammable and it does not leave environmentally hazardous wastes), expeditiousness $\left(\mathrm{CO}_{2}\right.$ penetrates into solid matrices more rapidly compared to liquid solvents), its selectivity (supercritical $\mathrm{CO}_{2}$ allows selective extraction of a wide range of analytes while leaving intact the bulk matrix) [10]. Due to the quadrupolar momentum, scCO2 can extract more polar compounds than $n$-hexane, and generally the addition of small percentages of co-solvents (such as ethanol and water) expands the extractable compounds window [11]. 
As additional tools, to assess the industrial interest of the technique, the scale-up of lab-data for industrial design is applicable by means of mathematical models, aiming at predicting the trend of compounds extraction from the matrices over time. The most frequently applied models describe the internal and external mass transfer as the main phenomena that normally occur in a packed bed as an extraction vessel [12]. Pressure, temperature, solid morphology, in terms of particle size, porosity and specific surface area, are the main physico-chemical parameters affecting the extraction and hence they are involved in the mathematical model.

The literature already reports the use of supercritical $\mathrm{CO}_{2}$ supported by mathematical models in the extraction of oil from green coffee beans, spent coffee ground and coffee husk [13]. Additionally, Couto and co-workers investigated the influence of pressure and temperature on the composition of oil obtained by supercritical $\mathrm{CO}_{2}$ treatment of spent coffee grounds [14]. This work was followed by a deeper technical and economic analysis by de Melo et al. on the same casestudy matrix [15].

To the best of our knowledge, no application of $\mathrm{sc}-\mathrm{CO}_{2}$ to silverskin has been attempted so far.

The main purpose of this work addresses to silverskin valorisation employing supercritical $\mathrm{CO}_{2}$, optimizing physico-chemical parameters (pressure and temperature) in the absence and presence of a co-solvent (ethanol) and comparing results in terms of yields and composition with conventional extraction methods, like Soxhlet. A mathematical model built aiming at predicting the extraction trend for further scale-up studies, design of experiment (DoE) and process optimization, is also presented as a complementary aspect towards real field applications.

\section{Experimental Section}

\section{Materials and Chemicals}

Micronized coffee silverskin (CS) was provided by an Italian roasting company. Caffeine, HPLC-grade and analytical grade organic solvents were purchased by Sigma-Aldrich Chemicals (Italy). 0.1 M sodium hydroxide $(\mathrm{NaOH})$ and $2 \mathrm{M}$ potassium hydroxide $(\mathrm{KOH})$ solutions were prepared by dilution of Titrisol ${ }^{\circledR}$ purchased from Merck. HPLC-grade water was obtained from a purification system (Millipore, Billerica, MA, USA). Carbon dioxide $\left(\mathrm{CO}_{2}\right)$ was furnished by Sapio s.r.l (Monza, Italy) with a purity of $99.999 \%$

\section{Soxhlet Extraction}

The extraction of coffee silverskin with Soxhlet apparatus was carried out to compare the yield and the chemical composition with $\mathrm{sc}-\mathrm{CO}_{2}$. Almost $10 \mathrm{~g}$ of CS were extracted with $100 \mathrm{~mL}$ of $n$-hexane for $6 \mathrm{~h}$, at reflux $\left(14 \mathrm{~mL} \mathrm{~min}^{-1}\right)$, until the feedstock was completely defatted. The organic solvent was therefore evaporated under vacuum (Buchi R210). The CS fat was analysed by gas chromatography (GC) and acid-base titration.

\section{Supercritical $\mathrm{CO}_{2}$ Extraction (sc- $\mathrm{CO}_{2}$ )}

sc- $\mathrm{CO}_{2}$ extractions were performed on SFT-XW110 apparatus (Supercritical Fluids Technology, inc., Newark, United States) equipped with an SFT-10 $\mathrm{CO}_{2}$ pump and $515 \mathrm{HPLC}$ pump (Waters, Italy) as secondary pump for organic modifiers. For each experiment, $40 \mathrm{~g}$ of micronized coffee silverskin were packed in the extraction vessel. The $\mathrm{CO}_{2}$ was pressurized in the vessel at different temperatures $(35,50$, $60{ }^{\circ} \mathrm{C}$ ) and pressures (200, 300 bar) with a constant flow rate of $15 \mathrm{~mL} \mathrm{~min}^{-1}$, for a maximum of $2 \mathrm{~h}$. The CS fat was collected in a vial at intervals of about 5, 15, 30, 60, $120 \mathrm{~min}$ to assess several data points for overall extraction curves (OECs). The extracts were then stored at $-20{ }^{\circ} \mathrm{C}$ for subsequent analysis. The extractions were performed in duplicate and data were expressed as means \pm standard deviation. Statistical analysis were conducted with Excel and Student's $t$-test was used. $p$-values $<0.05$ were considered significant.

\section{Total Fatty Acids Profile}

The chemical composition of CS fat was determined by gas chromatography HP-6890 (Agilent Technology, Italy) equipped with a flame ionized detector using a non-bonded, bis-cyanopropylpolysiloxane $(100 \mathrm{~m})$ capillary column at isotherm $\mathrm{T}=190{ }^{\circ} \mathrm{C}$. Before injection the samples $(10 \mathrm{mg}$ in $1 \mathrm{~mL}$ of $n$-hexane) were transesterified with a $2 \mathrm{M} \mathrm{KOH} /$ methanol solution $(0.200 \mathrm{~mL})$. The sample solution and the potassium hydroxide solution were manually shaked in a vial for five minutes and after settling the upper phase was injected for analysis.

\section{Free Fatty Acid (FFA) Value}

The FFA content of the CS fat was determined according to the method NGD C 10-1976. The fat sample (200-300 mg) was dissolved in $30 \mathrm{~mL}$ of a solution of ethyl ether/ethyl alcohol $(2: 1 \mathrm{v} / \mathrm{v})$. Then the mixture was titrated, under constant stirring, using phenolphthalein as indicator and a $\mathrm{NaOH}$ solution $(0.1 \mathrm{M})$. The FFA of the fat $(\mathrm{AV}, \mathrm{mg} \mathrm{NaOH}$ $\mathrm{g}^{-1}$ ) was determined according to Eq. (1):

$\% \mathrm{FFA}=\frac{V M M W}{m}$

where $\mathrm{V}(\mathrm{mL})$ is the volume of the sodium hydroxide solution used for the titration, $\mathrm{M}$ is the molarity of the $\mathrm{NaOH}$ 
solution $\left(\mathrm{mol} \mathrm{L}^{-1}\right)$, MW $\left(282 \mathrm{~g} \mathrm{~mol}^{-1}\right)$ is the molecular weight of oleic acid, and $\mathrm{m}(\mathrm{g})$ is the mass of the fat sample.

\section{Caffeine Content}

Caffeine was characterized and quantified using the Waters ACQUITY UPLC system (Waters corp., MA, United States) equipped with a quaternary pump, autosampler, thermostated column compartment and a dual-wavelength UV/Visible (UV/Vis) detector (TUV). The data were processed with Empower 3 workstations. The employed column was BEH $\mathrm{C}_{18}(2.1 \mathrm{~mm} \times 50 \mathrm{~mm})$ and mobile phase was composed of water containing $0.1 \%$ of formic acid (v/v) (A) and acetonitrile containing $0.1 \%$ of formic acid ( $\mathrm{v} / \mathrm{v})(\mathrm{B})$. The flow rate was set at $0.25 \mathrm{~mL} \mathrm{~min}^{-1}$ and the linear gradient elution was: 0 min, $95 \%$ A; 3 min, 93\% A; 7 min, 90\% A; $15 \min , 80 \%$ A; $17 \mathrm{~min}, 95 \% \mathrm{~A}$ with a re-equilibration time of $2 \mathrm{~min}$ before the next injection. The column temperature was maintained at $30^{\circ} \mathrm{C}$ and the wavelength set at $274 \mathrm{~nm}$. For the quantification of caffeine in the fat extract, a calibration curve was built using the method of external standard by means of a seven-points calibration curve with three replicate measurements for each calibration point. The curve was linear in a range of $100-0.0004 \mu \mathrm{g} \mathrm{mL}^{-1}$ with a calculated correlation coefficient $(R)$ of $0.9998(\mathrm{y}=57,797 \mathrm{x}+28,278)$. Results are displayed in Fig. 1 of Supporting Information (Fig. S1). Limit of detection (LOD) and limit of quantification (LOQ) were calculated as 3- and 10- fold the signal-to-noise ratio with a value of $0.06 \mathrm{ng} \mathrm{mL}^{-1}$ and $0.19 \mathrm{ng} \mathrm{mL}^{-1}$ respectively. The samples were dissolved in a limited amount of chloroform and diluted in an appropriate volume of acetonitrile to reach the desired concentration, then filtered by $0.45 \mu \mathrm{m}$ filter (Millex-FH, Millipore corp., MA, United States) before injection.

\section{Cost of Manufacturing (COM) Estimation of sc- $\mathrm{CO}_{2}$ Extraction Process}

The cost of manufacturing estimation $(\mathrm{COM})$ of $\mathrm{sc}-\mathrm{CO}_{2}$ extraction was evaluated using the methodology previously proposed by Turton et al. [16]. The COM is described in the following expression:

$$
\begin{aligned}
\mathrm{COM}= & 0.280 \times \mathrm{FCI}+2.73 \times \mathrm{COL} \\
& +1.23 \times\left(\mathrm{C}_{\mathrm{RM}}+\mathrm{C}_{\mathrm{WT}}+\mathrm{C}_{\mathrm{UT}}\right)
\end{aligned}
$$

where $\mathrm{FCI}$ is the fraction of investment. The cost of sc- $\mathrm{CO}_{2}$ laboratory apparatus was referred to that present in our laboratory, at Università degli Studi di Milano, that presents an extractor vessel of $0.1 \mathrm{~L}$ of capacity. The cost of industrial apparatus is reported to those calculated by De Melo et al. with two extractor vessels of $400 \mathrm{~L}$ of capacity, is $1,500,000.00 €[15,17]$. The depreciation rate was assumed to be $10 \%$ per year.

The operational labour cost $\left(C_{O L}\right)$ is generally divided into indirect and direct costs. This latter includes the wage of skilled men calculated as man-hour per operation-hour. The cost of $7920 \mathrm{~h}$ per year operational work, with continuous $24 \mathrm{~h}$ per day, $8 \mathrm{~h}$ daily shifts (three workers/shift) in 330 days. According to the table of Italian national chemical contract (CCNL) (http://www.filctemcgil.it), it can be assumed as $10.28 € / \mathrm{h}$.

$C_{R M}$ is the raw material cost. At the moment silverskin does not have any economic value on the market, and a hypothetic cost cannot be estimated.
Fig. 1 Conventional and non-conventional methods instrumental set-up and their corresponding extract products

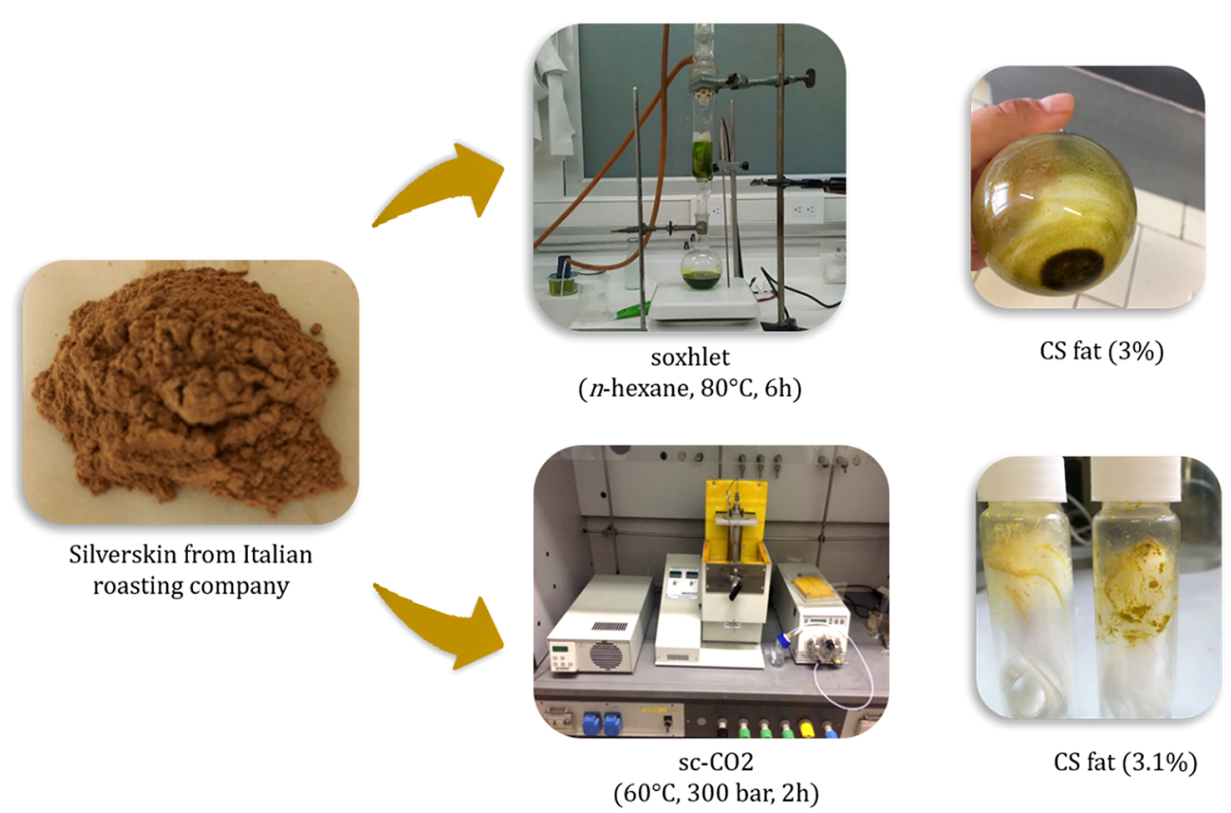


$C_{W T}$ is the waste treatment cost. In this case it is inexistent due to the further conversion of CS residue to second raw material for paper production.

Cost of utilities $\left(\mathrm{C}_{\mathrm{UT}}\right)$ is the sum of energetic costs associated to various processes as $\mathrm{CO}_{2}$ refrigeration and heater. In more detail, the energy consumption of sc- $\mathrm{CO}_{2}$ is the cost associated to: (i) chill liquid $\mathrm{CO}_{2}$ from ambient $20{ }^{\circ} \mathrm{C}$ to $4{ }^{\circ} \mathrm{C}$ at 58 bar for the liquefaction; (ii) pump the $\mathrm{CO}_{2}$ to extractor vessel from $4{ }^{\circ} \mathrm{C} / 58$ bar to $60{ }^{\circ} \mathrm{C} / 300 \mathrm{bar}$; (iii) maintain the supercritical extraction conditions $\left(60{ }^{\circ} \mathrm{C} / 300 \mathrm{bar}\right)$ for all extraction time $(2 \mathrm{~h})$.

The energetic calculations were performed using SimCentral of AVEVA using SRK as EoS considering the thermodynamic properties of gases shown by National Institute of Standards and Technology (NIST) [18]. The energy scale-up was performed linearly as reported by Prado et al. [19]. The price of electricity was referred to Italian annual energy consumption band $<20 \mathrm{MWh}$ calculated by Italian Regulatory Authority for Energy, Networks and Environment (ARERA).

Additionally, the $\mathrm{CO}_{2}$ tanks costs fall in the cost of utilities. The $\mathrm{CO}_{2}$ employed for the process was calculated to be $0.6 € / \mathrm{L}_{\text {gas }}$ according to Sapio s.r.l, Italy price and a loss of $2 \%$ was considered due to pressurize/depressurize operations. This cost can be considered negligible in the case of a specific apparatus for $\mathrm{CO}_{2}$ recovery is present in the industrial implant.

The economic cost of CS oil was calculated dividing the total oil extracted per the total raw material processed in 330 days.

\section{Results and Discussion}

\section{CS Fat Extraction}

In our experiments, the fat content in coffee silverskin (CS) was first evaluated by Soxhlet extraction, in the presence of a hydrocarbon solvent. Several research works reported that lipid fraction is estimated to be $2-3.4 \%$ calculated on the dry biomass, depending on the CS species (i.e. Arabica or Robusta) and geographical origins [20]. In agreement with literature data, the Soxhlet extraction of our material yielded $3.0 \% \pm 0.1$ (calculated on a dry weight basis) of a dark brown amorphous solid (Fig. 1). Similar results in term of yields were obtained with sc- $\mathrm{CO}_{2}$ in a considerably lower time respect to the reference method ( $2 \mathrm{~h}$ ) (Table 1$)$. In this case a light yellow amorphous solid with a texture similar to the butter was isolated, as displayed in Fig. 1. In order to investigate which physico-chemical parameters could influence the CS fat extraction, various temperature $\left(35,50,60^{\circ} \mathrm{C}\right)$ and pressure values $(200,300$ bar) were selected and combined at constant flow rate of $15 \mathrm{~mL} \mathrm{~min}^{-1}$ (Table 1).

As shown in Table 1, the extraction yields increase with pressure at constant temperature due to an increase of $\mathrm{CO}_{2}$ density, and thus the fluid capacity to solubilize the lipids from CS. Setting the pressure at medium-high value, the disruption of plant cell can be promoted, facilitating the release of compounds not previously extractable. In particular conditions (entry 2, 4 and 6 in Table 1), good extraction yields were obtained for each different temperature value specifically working at 300 bar. Tightly connected to pressure, the temperature is another important physical parameter that affects the $\mathrm{sc}-\mathrm{CO}_{2}$ extraction yield in a more complex way than pressure, as documented in the literature [21]. As reported in Table 1, an increment of CS fat yield was progressively observed in the range of temperature from 35 to $60{ }^{\circ} \mathrm{C}$, in both operative pressure values. However, at 200 bar similar yield values $(2.7 \pm 0.3 \%)$ were obtained for both the extractions conducted at $50{ }^{\circ} \mathrm{C}$ (Table 1 , entry 3 ) and $60{ }^{\circ} \mathrm{C}$ (Table 1 , entry 5). This is probably due to an increase in temperature causing a slightly negative effect on the density of sc- $\mathrm{CO}_{2}$ and thus on its solvation capacity. In parallel to this phenomenon, an increase of vapor pressure of the solutes can
Table 1 Experimental conditions for $\mathrm{CS}$ fat extraction by Soxhlet and $\mathrm{sc}-\mathrm{CO}_{2}$

\begin{tabular}{lllllll}
\hline Method & Data set & $\mathrm{T}\left({ }^{\circ} \mathrm{C}\right)$ & $\mathrm{p}(\mathrm{bar})$ & $\begin{array}{l}\text { Co-solvent } \\
(\% \mathrm{v} / \mathrm{v} \mathrm{EtOH})\end{array}$ & $\begin{array}{l}\text { Flow rate } \\
\left.(\mathrm{mL} \mathrm{min})^{-1}\right)\end{array}$ & Fat yield $\left(\mathrm{w}_{\mathrm{fat}} / \mathrm{w}_{\mathrm{dry} \mathrm{CS}}\right)$ \\
\hline Sc- $\mathrm{CO}_{2}$ & 1 & 35 & 200 & - & 15 & $2.1 \pm 0.2$ \\
& 2 & 35 & 300 & - & & $2.5 \pm 0.1$ \\
& 3 & 50 & 200 & - & $2.7 \pm 0.3$ \\
& 4 & 50 & 300 & - & $2.8 \pm 0.2$ \\
& 5 & 60 & 200 & - & $2.7 \pm 0.1$ \\
& 6 & 60 & 300 & - & $3.1 \pm 0.1$ \\
& 7 & 50 & 300 & 5 & & $3.3 \pm 0.3$ \\
& 8 & 60 & 300 & & - & $3.0 \pm 0.1$ \\
\hline
\end{tabular}

Results are presented as means \pm standard deviation of duplicate extractions ${ }^{*} p<0.05$, student's t-test two tailed 
be recorded that conversely enhances their own solubility in the supercritical fluid. Then moving to higher pressure, the density of sc- $\mathrm{CO}_{2}$ decreases moderately with a temperature increase and the second thermodynamic effect prevails, as observed in Table 1 entry 6 . The best extraction conditions were achieved at $300 \mathrm{bar}$ and $60{ }^{\circ} \mathrm{C}$ where these two opposite and parallel phenomena could be well balanced [14]. The addition of polar co-solvent in a variable percentage to $\mathrm{sc}-\mathrm{CO}_{2}$ is a common practice adopted for enhancing the amount and the selectivity of lipids extracted from a vegetable matrix [22]. Its principal action consists of increasing the local density around the solute molecule leading to specific bonds formation with solute molecules (i.e. dipole-dipole, H-bonds, etc.), thus improving their solubility in the solvent phase. Specifically, in this research work, ethanol was selected as polar additive considering its safe status (GRAS) and low toxicity to scout its effect on CS fat extraction. Furthermore, it was added in minimal percentage at the best extraction conditions previously identified, in a perspective of industrial process sustainability. The results showed an effective albeit small increment of the percentage of CS fat yield $(3.3 \pm 0.3 \%$ in Table 1 , entry 7$)$ respect to the use of pure sc- $\mathrm{CO}_{2}(3.1 \pm 0.1 \%$ in Table 1 entry 6$)$. On the other hand, the low percentage of ethanol and the high density of sc- $\mathrm{CO}_{2}$ at $60 \% 300$ bar cause a decrement of fat solubility with a negative impact on the extraction yield $(2.3 \pm 0.2 \%$ in Table 1, entry 8) addressed to liable crossover phenomenon in a ternary mixture. [22, 23] Noteworthy, the CS fat in all conditions tested, showed an improvement of organoleptic properties visually and to the touch respect to the Soxhlet extraction.

\section{Characterization of CS Fat}

The total fatty acids composition of CS butter obtained by sc- $\mathrm{CO}_{2}$ under various operative conditions and by Soxhlet extraction was analyzed by gas chromatography after transesterification and the results are reported in Table 2. In agreement with literature data [7], the main fatty acids in all samples are linoleic acid (C18:2) and palmitic acid (C16:0), present almost in the same $\% \mathrm{~mol}$, followed by oleic acid (C18:1) and stearic acid (C18:0). However, non-negligible amounts of long chain, high melting point arachidic (C20:0), behenic (C22:0) and lignoceric $(\mathrm{C} 24: 0)$ acid are also present. This unusual composition makes this fat of potential interest for the cosmetic industry. Moreover, it is different from that of other fats used in the formulation of cosmetic products such as shea or cocoa butter that contain only small amount $(<5 \%)$ of arachidic acid.

Basically the solubility of free fatty acids, alkyl esters of fatty acids, and mono-, di- and try-acylglycerols in sc- $\mathrm{CO}_{2}$ depends on their structural characteristics as the molecular weight and degree of unsaturation and it is influenced by the density of solvent [24].

It is very interesting to note that the chemical composition of fatty acids in terms of $\%$ mol varies upon the extraction conditions. In particular, the samples rich in medium-short chain saturated fatty acids with a lower amount of longsaturated chain fatty acids derived from extractions carried out under mild conditions (Table 2, entry 1 and 2). On the other hand, the use of stronger process conditions (Table 2, entry 3-6) provides a CS fat enriched in long-chain saturated fatty acids. Notably the \% mol of C24:0 in sample 6 resulted three times higher than sample 1 . This behaviour is again addressed to the increase of sc- $\mathrm{CO}_{2}$ density and the consequent increase of solvation power that promotes the solubilization of high weight fatty acids. Therefore, as well, the addition of co-solvent assisted the extraction of long-chain

(C22:0) and lignoceric acid (C24:0); saturated fatty acid (SFA); polyunsaturated/saturated fatty acid ratio (PUFA/SFA)
Table 2 Fatty acids (FA) profile of experimental extracts; myristic acid (C14:0), palmitic acid (C16:0), stearic acid (C18:0), oleic acid (C18:1), linoleic acid (C18:2), arachidic acid (C20:0), behenic acid

\begin{tabular}{|c|c|c|c|c|c|c|c|c|c|c|c|}
\hline \multirow[t]{2}{*}{$\mathrm{sc}-\mathrm{CO}_{2}$} & \multicolumn{8}{|c|}{ FA composition $(\% \mathrm{~mol})$} & \multirow[t]{2}{*}{ SFA } & \multirow[t]{2}{*}{ PUFA/SFA } & \multirow[t]{2}{*}{ FFA $(\% \mathrm{wt})$} \\
\hline & $\mathrm{C} 14: 0$ & $\mathrm{C} 16: 0$ & C18:0 & C18:1 & C18:2 & C20:0 & $\mathrm{C} 22: 0$ & $\mathrm{C} 24: 0$ & & & \\
\hline 1 & 0.5 & 39.5 & 6.8 & 10.5 & 34 & 4.6 & 2.3 & 0.4 & 54.1 & 0.83 & 21 \\
\hline 2 & 1.3 & 36.3 & 7.9 & 11.0 & 34.3 & 6.3 & 2.4 & 0.5 & 54.7 & 0.83 & 22.5 \\
\hline 3 & 0.7 & 35.2 & 7.7 & 10.1 & 32.7 & 7.4 & 4.5 & 0.6 & 56.1 & 0.76 & 19.2 \\
\hline 4 & 1.3 & 37.6 & 6.7 & 10.1 & 31.5 & 6.5 & 4.3 & 0.9 & 57.3 & 0.73 & 24.6 \\
\hline 5 & 0.5 & 32.8 & 7.2 & 10.0 & 30.5 & 9.0 & 8.1 & 1.3 & 58.9 & 0.69 & 19.8 \\
\hline 6 & 0.7 & 32.4 & 7.1 & 9.1 & 29.5 & 9.3 & 10.4 & 1.5 & 61.4 & 0.63 & 28.8 \\
\hline 7 & 1.1 & 34.4 & 6.8 & 9.5 & 29.8 & 7.9 & 7.7 & 1.3 & 58.1 & 0.68 & 26.5 \\
\hline 8 & 0.6 & 33.6 & 7.6 & 10.0 & 31.6 & 8.2 & 6.4 & 1.0 & 57.4 & 0.72 & 18.6 \\
\hline Soxhlet ( $n$-hexane) & - & 29.0 & 6.8 & 9.2 & 32.0 & 10.6 & 8.9 & 1.6 & 56.9 & 0.72 & 19.8 \\
\hline
\end{tabular}


fatty acids through the additive formation of specific solvent-solute bonds. (Table 2, entry 7 and 8) [22].

Noteworthy each component of the fat mixture gives its own contribution to the overall solubility of vegetal fat, not often predictable, in the supercritical fluid [25]. To sumup, the total content of saturated fatty acids (SFA) ranges between 54 and $61 \%$, while the polyunsaturated/saturated ratio (UFA/SFA) decreasing from mild to stronger conditions. It is also worth mentioning that the presence of behenic and lignoceric acids, not common in other vegetable oil, could make the CS fat a very attractive starting material for cosmetic formulations [26].

The content in free fatty acids is another important point to look at, in order to assess the quality and the field of application of a fat, as well as the possible changes occurring during its storage.

The acidity expressed as \% by weight of free fatty acids (FFA) obtained by titration of the samples extracted from silverskin was measured and it was found to be pretty high with respect to common vegetable oils, and the values obtained are reported in Table 2 . All the samples show an acidity in the range of $19-29 \%$, moderately higher with respect to the one observed for the Soxhlet extracts (19.8\%) [27]. The different extraction techniques therefore may affect the final fat acidity although no literature data are available in this respect.

Furthermore, the acidity slightly increases with the extraction pressure, despite the temperature. An explanation could be found in the variation of the physicochemical properties of $\mathrm{CO}_{2}$ at higher pressure enhancing the solubility of unsaponifiable compounds with free fatty acid-function [24]. This can explain as well as the increased yield at the same cited conditions (Table 2).

To the best of our knowledge, there are not studies reported in the literature evaluating deeply this aspect so far. On the basis of these results, we can conclude that sc- $\mathrm{CO}_{2}$ could be a straightforward method for obtaining extracts tunable and selective in terms of composition, suitable to be addressed for different purposes.

Besides fats, CS fat with traces of caffeine was expected to be collected, shown in Table 3. Caffeine is the principal bioactive component of coffee with a beneficial impact on the organism [28]. Several studies evidenced its presence as well in coffee silverskin in low percentage $(0.8-1.2 \%)$ conferring further attractive properties to this by-product. Caffeine inhibits lipid peroxidation induced by reactive oxygen species as hydroxyl radicals, peroxyl radicals and singlet oxygen acting as a protective agent for vegetal fat [29].

The physico-chemical characteristics of this xanthine explain its solubility in aprotic polar and solvents (chloroform, dichloromethane) as well as in supercritical dioxide [30], even at low temperature as $40{ }^{\circ} \mathrm{C}$ in a wide range of pressure (100-300 bar) [31].

The presence of caffeine was quantified in all samples in a variable amount in function of experimental parameters. In particular, the extraction yield of caffeine was influenced by temperature rather than pressure [31]. Figure 2 shows the temperature dependence of caffeine extraction yield at a fixed pressure of 200 and 300 bar. The isobar curves have the same trend, evidencing an increase of caffeine yield at $50{ }^{\circ} \mathrm{C}$ with a decrement at $60^{\circ} \mathrm{C}$ independently by pressure set. These anomalous results were similar to those obtained by Bandeira et $a l$. regarding the recovery of caffeine from green coffee oil [32]. Probably this can be explained either by the proximity to the critical point at those experimental conditions and the supercritical phase approaches the liquid phase density or by a lipids co-solvent effect.

Moreover, it is well documented that caffeine solubility can increase with the addition of polar additive that has a
Table 3 Caffeine extraction value at different experimental condition with a fixed flow rate of $15 \mathrm{~mL} \mathrm{~min}^{-1}$; caffeine was detected and quantified by UPLC-TUV (column BEH C18 $2.1 \times 50 \mathrm{~mm}, 1.7 \mathrm{um}$; mobile phase: water/ACN, flow rate: $0.250 \mathrm{~mL} \mathrm{~min}^{-1}$ )

\begin{tabular}{lllllll}
\hline Method & Data set & $\mathrm{T}\left({ }^{\circ} \mathrm{C}\right)$ & $\mathrm{p}(\mathrm{bar})$ & $\begin{array}{l}\text { Co-solvent } \\
(\% \mathrm{EtOH})\end{array}$ & $\begin{array}{l}\text { Extraction yield } \\
\left(\% \mathrm{w} / \mathrm{w}_{\mathrm{CS} \text { fat }}\right)\end{array}$ & $\begin{array}{l}\text { Extraction }_{\text {yield }}(\% \mathrm{w} / \\
\left.\mathrm{w}_{\mathrm{CS} \text { raw }}\right)\end{array}$ \\
\hline${\mathrm{sc}-\mathrm{CO}_{2}}$ & 1 & 35 & 200 & - & $2.4 \pm 0.3$ & $0.04 \pm 0.5$ \\
& 2 & & 300 & - & $1.6 \pm 0.4$ & $0.05 \pm 0.2$ \\
& 3 & 50 & 200 & - & $3.1 \pm 0.3$ & $0.08 \pm 0.2$ \\
& 4 & & 300 & - & $3.6 \pm 0.1$ & $0.10 \pm 0.1$ \\
& 5 & 60 & 200 & - & $2.8 \pm 0.1$ & $0.07 \pm 0.1$ \\
& 6 & & 300 & - & $3.0 \pm 0.2$ & $0.08 \pm 0.2$ \\
& 7 & 50 & 300 & 5 & $4.8 \pm 0.1$ & $0.14 \pm 0.1$ \\
& 8 & 60 & 300 & & $3.2 \pm 0.1$ & $0.08 \pm 0.2$ \\
Soxhlet $(n$-hexane $)$ & & & & & $0.7 \pm 0.2$ & $0.03 \pm 0.1$ \\
\hline
\end{tabular}

The amount is quantified on the extracted fraction

${ }^{a}$ Caffeine yield was calculated on the extracted CS fat

${ }^{\mathrm{b}}$ Caffeine yield was calculated on dry raw material 
Fig. 2 Dependence of caffeine extraction yield on temperature at a fixed pressure of $200 \mathrm{bar}$ (violet dots) and 300 bar (green dots) at a fixed extraction period of $2 \mathrm{~h}$. (Color figure online)

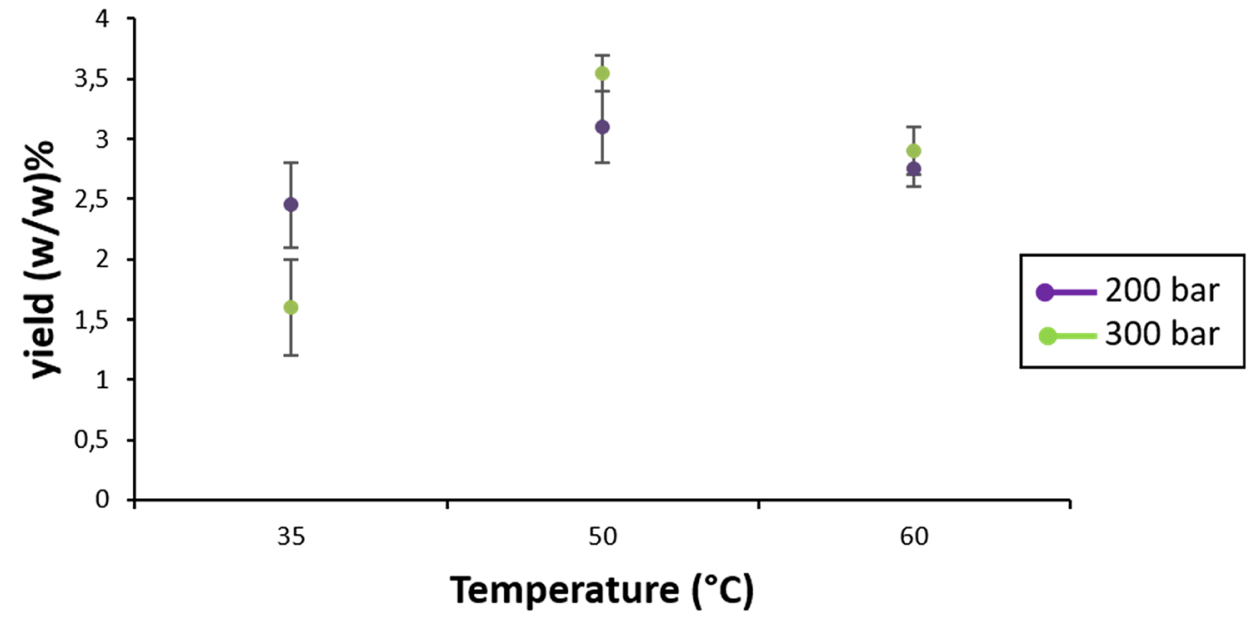

beneficial contribution on solvent density and specific solvent-solute bonds formation. In our case, the higher amount of caffeine was detected in the fat extracted with $5 \%$ of $\mathrm{EtOH}$ at $50{ }^{\circ} \mathrm{C} / 300$ bar $(4.8 \pm 0.1 \%$ in Table 3 , entry 7$)$ with a decrease co-solvent effect at $60{ }^{\circ} \mathrm{C}$ and a consequently lowered caffeine extraction $(3.2 \pm 0.1 \%$ Table 3 , entry 8$)$ due to a plausible reach of the critical temperature [33].

The amount of caffeine in CS fat, extracted with $n$-hexane in Soxhlet, was quite low $(0.7 \pm 0.2 \%$, Table 3$)$ compared to the values obtained in defined supercritical conditions, evidencing the suitability of $\mathrm{sc}-\mathrm{CO}_{2}$ in obtaining extracts enriched of structurally different compounds present in the same vegetal matrix.

\section{Mathematical Model}

The rationalization of experimental data toward a validated mathematical model is a fundamental step in view of industrial applications as scale-up, design of experiment (DoE) and process optimization. Application of this strategy as well as to CS fat extraction can furnish good indications for highlighting the sustainability of this procedure and can also be an inspiration to switch the direction of industrial processes.

With this aim, the collected extraction data were used in order to assess the feasibility of a further advanced mathematical analysis. In particular, the simplified dual-phase model described by Patel et al. was taken into account for this purpose [34]. It is based on the same fundamental equations of the model proposed by Sovová in 1993 [35] that found many applications. It has been demonstrated to possess good fitting capabilities [36-38] and an improved simplicity of the numerical solution.

The goodness of fit, the simplified mathematical approach and the analytical solution of such a model are the key reasons for the choice of the Patel et al. model for a preliminary mathematical assessment of the extraction system using supercritical carbon dioxide and coffee silverskin. The biological matrices used in sc- $\mathrm{CO}_{2}$ are composed mainly of cells which contain oils both inside and outside of the shell [39]. This distinction is used to model the $\mathrm{sc}-\mathrm{CO}_{2}$ extraction with the dual-phase principle used both in Sovová and Patel's models. In fact, the initial period of extraction represents the depletion of lipids found on the cells surface while the final period represents the extraction of lipids contained inside the cell structure. For these reasons, the initial period is typically faster since the external mass transfer is the controlling factor whilst in the final stage the extraction rate slows down until it zeroes, and the extraction effectively stops [40]. Those rates may be defined as, respectively, constant extraction rate (CER) and falling extraction rate (FER).

Some assumptions are used for the model as [34]: (i) axial flow with constant superficial velocity through a fixed bed of cylindrical shape, (ii) no radial dispersion, (iii) pure solvent at extractor entrance, (iv) constant temperature and pressure throughout the entire extraction, (v) homogenous physical properties of the solid phase, (vi) pseudo-steady state plug-flow, (vii) negligible accumulation of solute in the fluid phase. Moreover, an additional approximation is that of considering the extracted material as a single pseudo-component whose real composition is unknown to the model.

Mass balances for both fluid phase and solid phase are described, respectively, as [34]:

$\rho_{f} U \frac{\partial y}{\partial h}=J(x, y)$

$-\rho_{s}(1-\varepsilon) \frac{\partial x}{\partial t}=J(x, y)$

With initial conditions:

$x(h, t=0)=x_{0}$

$y(h=0, t)=0$ 
CER and FER mass transfer definitions are formulated as follows:

$J(x, y)=k_{f} a_{0} \rho_{f}\left(y_{r}-y\right) \quad$ for $x>x_{k}$

$J(x, y)=k_{s} a_{0} \rho_{s} x \quad$ for $x \leq x_{k}$

where $x_{k}$ is defined as the mass concentration of solute inside the solute-free solid at whose value the extraction transitions from constant to falling extraction rate.

By combining the initial conditions (Eqs. 5 and 6) with the mass balances (Eqs. 3 and 4) and the respective mass transfer it is possible to solve the differential system of equations and obtain:

$e=q y_{r}[1-\exp (-A)] \quad$ for $q<q_{m}$

$e=x_{0}-\exp \left[-B A\left(q-q_{m}\right)\right]\left[x_{0}-q_{m} y_{r}(1-\exp (-A))\right] \quad$ for $q \geq q_{m}$

where $e$ is defined as the dimensionless extracted mass, $q$ is the dimensionless fluid quantity used until a certain amount of time and $q_{m}$ is the value of $q$ for which the extraction shifts from the CER to the FER. Among the other parameters they can be defined as:

$A=\frac{k_{f} a_{0} H}{U}$

$B=k_{s} \rho_{s} / k_{f} \rho_{f}$

$q=\frac{U \rho_{f}}{H} \frac{1}{\rho_{s}(1-\varepsilon)} t$

$q_{m}=\frac{x_{0}-x_{k}}{y_{r} A}$

$A$ depends mainly on the fluid dynamics of the system and from an operational point of view, it is dependent only on the flow rate; $k_{f}$ is the fluid mass transfer coefficient and depends on the properties of the fluid and the flow regime; $a_{0}$ is the superficial mass coefficient and depends only on the solid matrix; $H$ is the column height that is commonly fixed.
$B$ is the ratio between the solid mass transfer coefficient $k_{s}$ and solid density $\rho_{s}$, which both depend only on the solid phase, and the fluid mass transfer $k_{f}$ and the fluid density $\rho_{s}$.

$x_{0}$ and $y_{r}$ in $q_{m}$ represent, respectively, the initial solid mass fraction of solute in the solid matrix and the solubility of lipids in the supercritical fluid. For a more in-depth analysis of the variables presented, please refer to [34].

\section{Model Application}

The best extraction conditions obtained (Table 1, entry 6) were considered as the starting values for the model application. Further and tailor-made experimental conditions were carried out to boost the model (Table 4). The operative conditions evaluated are primarily the initial mass of solid and flow rate, parameters $m_{0}$ and $Q$ respectively (Table 4). The idea behind this choice is to test the applicability of the model in different fluid-dynamic conditions. It is worth note that fluid-dynamic is probably one of the most complex aspects of modeling the supercritical fluid extraction. The flow regime depends on several factors, most importantly: the shape and size of the solid matrix, the porosity of the particles, the column geometry, the flow rate and the void factor inside the column. The only operative conditions that we can properly control in this list are the flow rate $(Q)$ and the void factor inside the column. This last parameter is controlled by the quantity of solid initially charged in the vessel, namely $m_{0}$. As discussed before, temperature and pressure affect the density of the supercritical carbon dioxide and its solvent capacity playing a key role in process optimization. For the aforementioned reasons, six new sets of experimental data were produced purposely to test the model in different fluid dynamics conditions around the optimal pressure and temperature conditions for maximum yield. With this aim, several data points have been collected in time (Fig. S2) and a non-linear regression with the described model was performed on each set. The non-linear regression is conducted by minimizing the sum of least squares function between the experimental data and the prediction provided by the model by means of varying the model parameters. Thus, the found set of parameters is to be considered the best-fit parameters for each experimental set [41]. As reported in Table 4, the model fit was evaluated with both the average absolute relative deviation (AARD) and the standard error of the estimate
Table 4 Operative condition and non-linear regression best-fit parameters of the dual-phase Patel model based on the additional experimental results, $\mathrm{T}\left({ }^{\circ} \mathrm{C}\right), \mathrm{P} 300$ (bar), Q $\left(\mathrm{ml} \mathrm{min}{ }^{-1}\right), \mathrm{m}_{0}(\mathrm{~g}), \operatorname{AARD}(\%)$

\begin{tabular}{lllllllllll}
\hline Data set & $T$ & $Q$ & $\mathrm{~m}_{0}$ & $x_{0}$ & $y_{r}$ & $A$ & $B$ & $q_{m}$ & $A A R D$ & $S$ \\
\hline 1 & 60 & 15 & 42.002 & 0.0293 & 0.0100 & 0.1582 & 0.1355 & 7.9797 & 4.38 & 0.0004457 \\
2 & 60 & 20 & 40.825 & 0.0339 & 0.0157 & 0.2597 & 0.1648 & 6.8733 & 2.80 & 0.0005465 \\
3 & 60 & 15 & 28.204 & 0.0318 & 0.0142 & 0.2105 & 0.1461 & 5.2405 & 0.92 & 0.0003085 \\
4 & 60 & 20 & 28.240 & 0.0228 & 0.0048 & 0.0494 & 0.1193 & 3.5370 & 1.07 & 0.0000551 \\
5 & 60 & 20 & 40.669 & 0.0547 & 0.0257 & 0.2035 & 0.0691 & 3.8467 & 1.89 & 0.0008240 \\
\hline
\end{tabular}


(S). The AARD values of the regressions were quite low, except for the first data set. This indicated that the model has a better performance towards fitting experimental data, thus it should be preferred.

A visual inspection of the plots reported in Fig. 3 shows the fitting quality of the described model. Moreover, it can be noted the point where the phase inversion happens, and the extraction shifts from the constant extraction rate, which is a straight line, towards the falling extraction rate, which is similar to an inverse exponential curve.

To sum up, the model fits successfully the preliminary experimental data provided. This results in a possible decomposition of all the constituent parameters of the model and in their derivatization with a fundamental approach to reduce the number of parameters to be fitted. Noteworthy, this method could allow us to transform the model from a purely regressive to a predictive model. Moreover, the implementation of a proper design of experiments (DoE) can be a suitable tool for collecting a range of experimental data to cover the whole application domain of the model and find the best fit fundamental parameters. This leads to a possible optimization of the best operative conditions and maximization of the yield of extraction, and finally to design scale-up.

\section{Economic and Energy Evaluation of CS Fat sc- $\mathrm{CO}_{2}$ Extraction Scale-Up}

A preliminary cost of manufacturing (COM) of an annual sc- $\mathrm{CO}_{2}$ extraction of $\mathrm{CS}$ fat was estimated on laboratory data fitting the mathematical model, and then the results were projected at industrial scale for a preliminary economic estimation.

COM is the sum of several invoices that cannot be generalized but they need to be evaluated case for case. CS fat represents a novelty in the chemical market for which reason its cost on the market cannot be still evaluated. The preliminary estimation of the CS fat COM extracted by sc- $\mathrm{CO}_{2}$ is $€ \mathrm{~kg}^{-1}$ $1,479.83$ and 31.16 for small and large scale. As expected, the costs are reduced with the increase of extraction scale [17]. Moreover the cost of CS fat is in alignment with the costs of other vegetal oil derived from agri-food waste used as raw material such as maize stover $\left(88.89 € \mathrm{~kg}_{\text {oil }}{ }^{-1}\right)$ [42] and cupuassu defatted seed $\left(40.46 \$ \mathrm{Kg}_{\mathrm{oil}}{ }^{-1}\right)$ [43]. Certainly, the cost of CS fat production will be affected by the other variable overheads whose could not be estimated so far.

It is worth to note that the fixed capital investment (FCI), commonly addressed to the cost of supercritical fluid extractor, covers an onerous weight in the formula. However, the advantage in this investment can be notable especially when the economic return of fat selling is considerable. The second factor that mainly affects the COM is the raw material costs $\left(\mathrm{C}_{\mathrm{RM}}\right)$ and in the case of expensive and precious raw material, its management can influence as well as FCI and cost of labor $\left(\mathrm{C}_{\mathrm{OL}}\right)$ voices. On the other hand, the cost of raw material can be abated and/or amortized in two cases:

(1) The raw material is an agri-food waste without any economic value abated [44].

(2) The fresh and or the impoverished raw material can be burned to furnish the energy required to heat the instrument for the next extraction cycle, affecting positively the cost of utilities $\left(\mathrm{C}_{\mathrm{UT}}\right)$ as proved by Attard et al. in the case of maize stover $[42,45]$.

The realization of the latter case can have a positive influence as well as on the cost of waste disposal $\left(\mathrm{C}_{\mathrm{WT}}\right)$ highlighting the possibility of an energy and/or an economic return. In the specific case, defatted silverskin results to be still attractive for other industrial sectors as paper-making given the richness in cellulose. The entry in a new productive cycle, not only abated the waste material disposal cost but, in full accordance with the hinge of the circular
Fig. 3 Non-linear regression results of the dualphase Patel et al. model of the first experimental set $\left(60{ }^{\circ} \mathrm{C} / 300 \mathrm{bar} / 12 \mathrm{~mL} \mathrm{\textrm {min } ^ { - 1 } )}\right.$ (circles) and the fourth experimental set $\left(60{ }^{\circ} \mathrm{C} / 300 \mathrm{bar} / 20 \mathrm{~mL} \mathrm{~min}{ }^{-1}\right)$ (crosses)

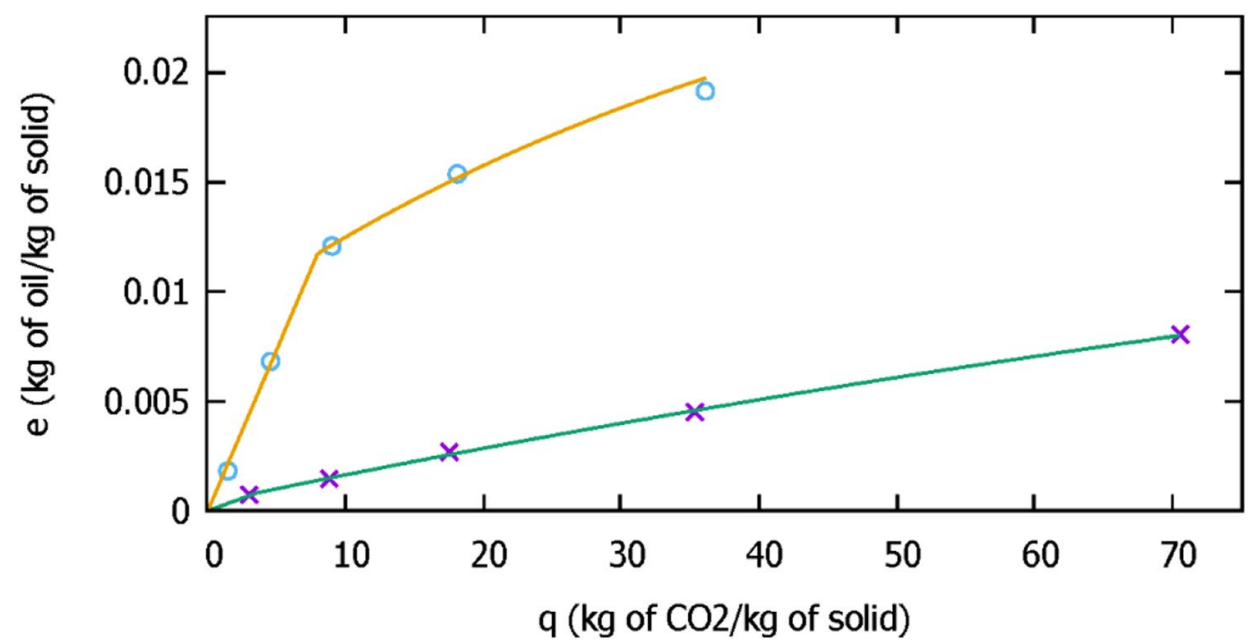


economy, becomes a secondary raw material for a new production process. [46, 47]

For both the sc- $\mathrm{CO}_{2}$ and the traditional Soxhlet process, the start-up or dynamic phases of the operations were not considered, thus the energy consumption is the continuous, constant, set-point operative values. The fluid thermodynamic properties are calculated only by considering the pure single component non-ideal fluid and neglecting the contribution of the extracted lipids for both the $\mathrm{sc}-\mathrm{CO}_{2}$ and the Soxhlet processes.

The energy consumption, included in $\mathrm{C}_{\mathrm{UT}}$ costs, has been estimated to be $172.87 \mathrm{~kJ} \mathrm{~h}^{-1}$ for the small scale of $0.1 \mathrm{~L}$ with a setpoint of $60^{\circ} \mathrm{C}$ and 4350 psi in the extractor column and a constant massive flow rate of $1.13 \mathrm{~kg} \mathrm{~h}^{-1}$ and, via a linear scale-up for a large scale of $400 \mathrm{~L}$, to be $6.91 * 10^{5} \mathrm{~kJ} / \mathrm{h}$ with a massive flow rate of $4512.22 \mathrm{~kg} \mathrm{~h}^{-1}$ (Fig. S3). The total energy requirement for the aforementioned lab-scale conditions was calculated for an average extraction time of $2 \mathrm{~h}$ is $345.74 \mathrm{~kJ}$. From a purely energetical point of view, the energetic cost increases linearly as the supercritical extractor gets bigger. In fact, if the fat yield per flow-rate is maintained constant between the lab- and the industrial scale, then the energy cost increases linearly since it is mainly related to the flow-rate of sc- $\mathrm{CO}_{2}$ set in the system [19]. However, for the industrial scale it is more common to introduce $\mathrm{CO}_{2}$ recycles and several energy recovery systems which will lead to more energy efficient operations with respect to the more trivial lab-scale equipment.

On the other hand, the extraction of CS fat carried out by Soxhlet can be apparently cost-effective and more advantageous by an energy point of view. It is enough to think of the simplicity of the apparatus being composed only by a round bottom flask with different capacity, a condenser, and the extractor chamber. A preliminary energy consumption calculation evidenced that Soxhlet extractor, at the small scale, may require an ideal minimum of $352.71 \mathrm{~kJ} \mathrm{~h}^{-1}$ with the experimental reflux flow rate of $14 \mathrm{~mL} \mathrm{~min}^{-1}$, since the whole extraction process needs $6 \mathrm{~h}$ to reach the same results of the sc- $\mathrm{CO}_{2}$ extraction, in terms of yield, the total energy consumption is $2116.26 \mathrm{~kJ}$. This data confirms that the Soxhlet not only is a time consuming method but it has an energy requirement similar to that calculated for $\mathrm{sc}-\mathrm{CO}_{2}$, as already evidenced by Virot et al. [48].

To sum up, CS fat extraction is affordable to scale-up by SFE. The relative high capital investment cost required in SFE process is great compensated by numerous benefits: low $\mathrm{CO}_{2}$ cost and batch times, higher recovery and quality of desired compounds, absence of pollution treatment costs. The fat obtained by Soxhlet requires additional manufacturing processes (drying and preserving) to reach a suitable quality for further applications, especially demanded in cosmetic field. These additional steps are not necessary for the fatty material extracted by $\mathrm{sc}-\mathrm{CO}_{2}$. In fact, as shown in this work, the $\mathrm{CS}$ butter isolated by $\mathrm{sc}-\mathrm{CO}_{2}$ showed unique organoleptic properties, specifically well appreciated by cosmetic industrial partners. This is helpful to dictate the market price and amortizes the fixed cost invested (i.e. apparatus).

\section{Conclusions}

This work demonstrates that silverskin, the only by-product of coffee roasting, can be successfully valorised yielding an added-value semi-solid fat by means of a green extraction technique like supercritical $\mathrm{CO}_{2}$, whose laboratory conditions can be easily scaled up in industrial plants. In addition, industrial sc- $\mathrm{CO}_{2}$ plants have the possibility to recover clean $\mathrm{CO}_{2}$ used in the process, guaranteeing a waste-free, safe and low-cost extraction process. No further waste was generated by this process given that the cellulosic residue is recovered in another way, becoming a second raw material for paper production.

Moreover, the feasibility of CS fat extraction in industrial processes is also supported by the mathematical model. In fact, our results demonstrated that the mathematical model is able to fit experimental data with good performance and the transformation from a purely regressive to a predictive model will enable us to plan a possible optimization of the extraction conditions and also a future scale-up design. Although without impressive differences in terms of yield between the conventional $(3.0 \pm 0.1 \%)$ and the best $\mathrm{sc}-\mathrm{CO}_{2}$ process conditions $\left(3.1 \% \pm 0.1,60{ }^{\circ} \mathrm{C} / 300\right.$ bar $)$, the extraction time was drastically reduced from 6 to $2 \mathrm{~h}$ avoiding the use of hydrocarbon or chlorinated solvents. The addition of a safe and non-toxic organic modifier as $\mathrm{EtOH}(5 \%, \mathrm{v} / \mathrm{v}) \mathrm{did}$ not remarkably improve the extraction yield respect to the use of pure $\mathrm{CO}_{2}$, contributing only to enhance the caffeine amount in the CS fat.

The specificity of CS fat composition can be modulated by properly tuning pressure and temperature. All extracts showed an interesting fatty acid profile enriched by caffeine, an organic antioxidant, making the CS fat unique starting material. The preliminary economic analysis of CS extraction has highlighted how the use of an agri-food waste as a source of natural fat has a favourable influence on the COM, helping to amortize the plant cost.

The calculated energetic consumption at small scale of the sc- $\mathrm{CO}_{2}$ process $\left(172.87 \mathrm{~kJ} \mathrm{~h}^{-1}\right)$ compared to the Soxhlet extraction $\left(352.71 \mathrm{~kJ} \mathrm{~h}^{-1}\right)$ is similar, however, the first technology has an enormous advantage which is that of avoiding the need of the organic solvent disposal and related costs, thus reducing any negative impact on the environment. It is worth to mention that the residue from supercritical extraction (c.a. 90-95\% w/w) is a powder deprived of bioactive components, thus resulting in almost pure cellulose, available to further processing and waste valorisation. All 
these characteristics, together with the eco-sustainability of the extraction process, make this by-products-derived fatty material very attractive for various industrial fields as cosmetic.

This research work is a frame of a multidisciplinary project aimed at all-round valorizing coffee silverskin in Italian scenario, but potentially applicable to other countries where coffee manufacturing is massive.

Supplementary Information The online version contains supplementary material available at https://doi.org/10.1007/s12649-021-01435-9.

Acknowledgement The authors are grateful to Cariplo Foundation and Innovhub for the financial support to Circular Coffee Project (CirCO project-http://progettocirco.it/, Grant No. 2017-0988).

Author Contributions The manuscript was written through contributions of all authors. All authors have given approval to the final version of the manuscript. LV, NR, FM, GB: supervision; NR, FZ and LV: funding acquisition; RN, LV and NR: conceptualization; AG: software, validation, formal analysis; RN, FZ, AG: investigation, methodology, writing-original draft; SM writing-review and editing.

Funding Open access funding provided by Università degli Studi di Milano within the CRUI-CARE Agreement.

\section{Declarations}

Conflict of interest The authors declare that they have no conflict of interest.

Open Access This article is licensed under a Creative Commons Attribution 4.0 International License, which permits use, sharing, adaptation, distribution and reproduction in any medium or format, as long as you give appropriate credit to the original author(s) and the source, provide a link to the Creative Commons licence, and indicate if changes were made. The images or other third party material in this article are included in the article's Creative Commons licence, unless indicated otherwise in a credit line to the material. If material is not included in the article's Creative Commons licence and your intended use is not permitted by statutory regulation or exceeds the permitted use, you will need to obtain permission directly from the copyright holder. To view a copy of this licence, visit http://creativecommons.org/licenses/by/4.0/.

\section{References}

1. Geissdoerfer, M., Savaget, P., Bocken, N.M.P., Hultink, E.J.: Circular economy sustainability paradigm. J. Clean. Prod. 143, 757-768 (2019). https://doi.org/10.1016/j.jclepro.2016.12.048. Abstract

2. Fatih Demirbas, M., Balat, M., Balat, H.: Biowastes-to-biofuels. Energy Convers. Manag. 52, 1815-1828 (2011). https://doi.org/ 10.1016/j.enconman.2010.10.041

3. Silveira, S.T., Daroit, D.J., Brandelli, A.: Pigment production by Monascus purpureus in grape waste using factorial design. LWT: Food Sci. Technol. 41, 170-174 (2008). https://doi.org/10.1016/j. lwt.2007.01.013

4. Murthy, P.S., Madhava Naidu, M.: Sustainable management of coffee industry by-products and value addition: a review. Resour.
Conserv. Recycl. 66, 45-58 (2012). https://doi.org/10.1016/j.resco nrec.2012.06.005

5. Toschi, T.G., Cardenia, V., Bonaga, G., Mandrioli, M., RodriguezEstrada, M.T.: Coffee silverskin: characterization, possible uses, and safety aspects. J. Agric. Food Chem. 62, 10836-10844 (2014). https://doi.org/10.1021/jf503200z

6. Narita, Y., Inouye, K.: Review on utilization and composition of coffee silverskin. Food Res. Int. 61, 16-22 (2014). https://doi.org/ 10.1016/j.foodres.2014.01.023

7. Costa, A.S.G., Alves, R.C., Vinha, A.F., Costa, E., Costa, C.S.G., Nunes, M.A., Almeida, A.A., Santos-Silva, A., Oliveira, M.B.P.P.: Nutritional, chemical and antioxidant/pro-oxidant profiles of silverskin, a coffee roasting by-product. Food Chem. 267, 28-35 (2018). https://doi.org/10.1016/j.foodchem.2017.03.106

8. Bresciani, L., Calani, L., Bruni, R., Brighenti, F., Del Rio, D.: Phenolic composition, caffeine content and antioxidant capacity of coffee silverskin. Food Res. Int. 61, 196-201 (2014). https:// doi.org/10.1016/j.foodres.2013.10.047

9. Costa, A.S.G., Alves, R.C., Vinha, A.F., Barreira, S.V.P., Nunes, M.A., Cunha, L.M., Oliveira, M.B.P.P.: Optimization of antioxidants extraction from coffee silverskin, a roasting by-product, having in view a sustainable process. Ind. Crops Prod. 53, 350-357 (2014). https://doi.org/10.1016/j.indcrop.2014.01.006

10. Pereira, C.G., Meireles, M.A.A.: Supercritical fluid extraction of bioactive compounds: fundamentals, applications and economic perspectives. Food Bioprocess Technol. 3, 340-372 (2010). https://doi.org/10.1007/s11947-009-0263-2

11. Manna, L., Bugnone, C.A., Banchero, M.: Valorization of hazelnut, coffee and grape wastes through supercritical fluid extraction of triglycerides and polyphenols. J. Supercrit. Fluids 104, 204-211 (2015). https://doi.org/10.1016/j.supflu.2015.06.012

12. Del Valle, J.M., De La Fuente, J.C.: Supercritical $\mathrm{CO}_{2}$ extraction of oilseeds: review of kinetic and equilibrium models. Crit. Rev. Food Sci. Nutr. 46, 131-160 (2006). https://doi.org/10.1080/ 10408390500526514

13. Cornelio-Santiago, H.P., Gonçalves, C.B., de Oliveira, N.A., de Oliveira, A.L.: Supercritical $\mathrm{CO}_{2}$ extraction of oil from green coffee beans: solubility, triacylglycerol composition, thermophysical properties and thermodynamic modelling. J. Supercrit. Fluids 128, 386-394 (2017). https://doi.org/10.1016/j.supflu. 2017.05.030

14. Couto, R.M., Fernandes, J., da Silva, M.D.R.G., Simões, P.C.: Supercritical fluid extraction of lipids from spent coffee grounds. J. Supercrit. Fluids 51, 159-166 (2009). https://doi.org/10.1016/j. supflu.2009.09.009

15. De Melo, M.M.R., Barbosa, H.M.A., Passos, C.P., Silva, C.M.: Supercritical fluid extraction of spent coffee grounds: measurement of extraction curves, oil characterization and economic analysis. J. Supercrit. Fluids 86, 150-159 (2014). https://doi.org/ 10.1016/j.supflu.2013.12.016

16. Turton, R., Bailie, R.C., Whiting, W.B., Shaeiwitz, J.A.: Analysis, Design and Synthesis of Chemical Processes. Prentice Hall, Upper Saddle River (2009)

17. Rosa, P.T.V., Meireles, M.A.A.: Rapid estimation of the manufacturing cost of extracts obtained by supercritical fluid extraction. J. Food Eng. 67, 235-240 (2005). https://doi.org/10.1016/j.jfood eng.2004.05.064

18. Lemmon, E.C., McLinden, M.O., Friend, D.C.: Thermophysical properties of fluid systems. In: Linstrom, P.J., Mallard, W.G. (eds.) NIST Chemistry WebBook NIST Standard Reference Database Number 69, p. 20899. National Institute of Standards and Technology, Gaithersburg (2020)

19. Prado, J.M., Prado, G.H.C., Meireles, M.A.A.: Scale-up study of supercritical fluid extraction process for clove and sugarcane residue. J. Supercrit. Fluids 56, 231-237 (2011). https://doi.org/ 10.1016/j.supflu.2010.10.036 
20. Bessada, S.M.F., Alves, R.C., Costa, A.S.G., Nunes, M.A., Oliveira, M.B.P.P.: Coffea canephora silverskin from different geographical origins: a comparative study. Sci. Total Environ. 645, 1021-1028 (2018). https://doi.org/10.1016/j.scitotenv.2018. 07.201

21. Reverchon, E., De Marco, I.: Supercritical fluid extraction and fractionation of natural matter. J. Supercrit. Fluids 38, 146-166 (2006). https://doi.org/10.1016/j.supflu.2006.03.020

22. Güçlü-Üstündağ, Ö., Temelli, F.: Solubility behavior of ternary systems of lipids, cosolvents and supercritical carbon dioxide and processing aspects. J. Supercrit. Fluids 36, 1-15 (2005). https:// doi.org/10.1016/j.supflu.2005.03.002

23. Quitain, A.T., Oro, K., Katoh, S., Moriyoshi, T.: Recovery of oil components of okara by ethanol-modified supercritical carbon dioxide extraction. Bioresour. Technol. 97, 1509-1514 (2006). https://doi.org/10.1016/j.biortech.2005.06.010

24. Güçlü-Üstündağ, Ö., Temelli, F.: Correlating the solubility behavior of fatty acids, mono-, di-, and triglycerides, and fatty acid esters in supercritical carbon dioxide. Ind. Eng. Chem. Res. 39, 4756-4766 (2000). https://doi.org/10.1021/ie0001523

25. Sovová, H., Zarevúcka, M., Vacek, M., Stránský, K.: Solubility of two vegetable oils in supercritical $\mathrm{CO}_{2}$. J. Supercrit. Fluids 20, 15-28 (2001). https://doi.org/10.1016/S0896-8446(01)00057-2

26. Chow Ching, K.: Fatty Acids in Foods and Their Health Implication. CRC Press, Boca Raton (2008)

27. Pengkumsri, N., Chaiyasut, C., Sivamaruthi, B.S., Saenjum, C., Sirilun, S., Peerajan, S., Suwannalert, P., Sirisattha, S., Chaiyasut, K., Kesika, P.: The influence of extraction methods on composition and antioxidant properties of rice bran oil. Food Sci. Technol. 35, 493-501 (2015). https://doi.org/10.1590/1678-457X.6730

28. McLellan, T.M., Caldwell, J.A., Lieberman, H.R.: A review of caffeine's effects on cognitive, physical and occupational performance. Neurosci. Biobehav. Rev. 71, 294-312 (2016). https://doi. org/10.1016/j.neubiorev.2016.09.001

29. Devasagayam, T.P.A., Kamat, J.P., Mohan, H., Kesavan, P.C.: Caffeine as an antioxidant: inhibition of lipid peroxidation induced by reactive oxygen species. Biochim. Biophys. Acta: Biomembr. (1996). https://doi.org/10.1016/0005-2736(96)00040-5

30. Edwards, Q.A., Lunat, I., Neale, L.D.G., Kulikov, S.M.: Waterorganic solvent. Media 13, 1218-1226 (2015)

31. De Oliveira, P.M.A., De Almeida, R.H., De Oliveira, N.A., Bostyn, S., Gonçalves, C.B., De Oliveira, A.L.: Enrichment of diterpenes in green coffee oil using supercritical fluid extraction: characterization and comparison with green coffee oil from pressing. J. Supercrit. Fluids 95, 137-145 (2014). https://doi.org/10. 1016/j.supflu.2014.08.016

32. Bandeira, Á., Azevedo, A.D., Kieckbusch, T.G., Tashima, A.K., Sadeg, R., Mazzafera, P., Alexandre, S., Vieira, B.: Solubility data and modeling. Artigo 31, 1319-1323 (2008)

33. Kopcak, U., Mohamed, R.S.: Caffeine solubility in supercritical carbon dioxide/co-solvent mixtures. J. Supercrit. Fluids 34, 209-214 (2005). https://doi.org/10.1016/j.supflu.2004.11.016

34. Patel, R.N., Bandyopadhyay, S., Ganesh, A.: A simple model for super critical fluid extraction of bio oils from biomass. Energy Convers. Manag. 52, 652-657 (2011). https://doi.org/10.1016/j. enconman.2010.07.043

35. Sovová, H.: Rate of the vegetable oil extraction with supercritical $\mathrm{CO}_{2}$-I. Modelling of extraction curves. Chem. Eng. Sci. 49, 409-414 (1994). https://doi.org/10.1016/0009-2509(94)87012-8

36. Andrade, K.S., Gonalvez, R.T., Maraschin, M., Ribeiro-Do-Valle, R.M., Martínez, J., Ferreira, S.R.S.: Supercritical fluid extraction from spent coffee grounds and coffee husks: antioxidant activity and effect of operational variables on extract composition. Talanta 88, 544-552 (2012). https://doi.org/10.1016/j.talanta.2011.11.031
37. Martínez, J., Monteiro, A.R., Rosa, P.T.V., Marques, M.O.M., Meireles, M.A.A.: Multicomponent model to describe extraction of ginger oleoresin with supercritical carbon dioxide. Ind. Eng. Chem. Res. 42, 1057-1063 (2003). https://doi.org/10.1021/ie020 694f

38. Mezzomo, N., Martínez, J., Ferreira, S.R.S.: Supercritical fluid extraction of peach (Prunus persica) almond oil: kinetics, mathematical modeling and scale-up. J. Supercrit. Fluids 51, 10-16 (2009). https://doi.org/10.1016/j.supflu.2009.07.008

39. Brunner, G.: Mass transfer from solid material in gas extraction. Berichte der Bunsengesellschaft für Phys. Chemie. 88, 887-891 (1984). https://doi.org/10.1002/bbpc.19840880923

40. Del Valle, J.M., Napolitano, P., Fuentes, N.: Estimation of relevant mass transfer parameters for the extraction of packed substrate beds using supercritical fluids. Ind. Eng. Chem. Res. 39, 47204728 (2000). https://doi.org/10.1021/ie000034f

41. Seber, G.A.F.., Wild, C.J.: Nonlinear Regression. Wiley, Hoboken (2003)

42. Attard, T.M., McElroy, C.R., Hunt, A.J.: Economic assessment of supercritical $\mathrm{CO}_{2}$ extraction of waxes as part of a maize stover biorefinery. Int. J. Mol. Sci. 16, 17546-17564 (2015). https://doi. org/10.3390/ijms160817546

43. Cavalcanti, R.N., Albuquerque, C.L.C., Meireles, M.A.A.: Supercritical $\mathrm{CO}_{2}$ extraction of cupuassu butter from defatted seed residue: experimental data, mathematical modeling and cost of manufacturing. Food Bioprod. Process. 97, 48-62 (2016). https:// doi.org/10.1016/j.fbp.2015.10.004

44. Huang, Z., Ma, Q., Liu, S.F., Guo, G.M.: Benign recovery of carotenoids from Physalis alkekengi L. var. francheti through supercritical $\mathrm{CO}_{2}$ extraction: yield antioxidant activity and economic evaluation. J. CO2 Util. 36, 9-17 (2020). https://doi.org/ 10.1016/j.jcou.2019.10.015

45. Attard, T.M., McElroy, C.R., Gammons, R.J., Slattery, J.M., Supanchaiyamat, N., Kamei, C.L.A., Dolstra, O., Trindade, L.M., Bruce, N.C., McQueen-Mason, S.J., Shimizu, S., Hunt, A.J.: Supercritical $\mathrm{CO}_{2}$ extraction as an effective pretreatment step for wax extraction in a miscanthus biorefinery. ACS Sustain. Chem. Eng. 4, 5979-5988 (2016). https://doi.org/10.1021/acssuschem eng. $6 \mathrm{~b} 01220$

46. Cordella, M., Kaps, R.: Sustainability of Bio-based Products: Linking Life Cycle Thinking with Standards, Certification and Labelling Schemes. Springer, Cham (2018)

47. Hidalgo, D., Martín-Marroquín, J.M., Corona, F.: A multi-waste management concept as a basis towards a circular economy model. Renew. Sustain. Energy Rev. 111, 481-489 (2019). https://doi.org/ 10.1016/j.rser.2019.05.048

48. Virot, M., Tomao, V., Colnagui, G., Visinoni, F., Chemat, F.: New microwave-integrated Soxhlet extraction. An advantageous tool for the extraction of lipids from food products. J. Chromatogr. A 1174, 138-144 (2007). https://doi.org/10.1016/j.chroma.2007.09. 067

49. Pirovano, C., Saligari, F., Faccini, I., Valsesia, P., Bettinelli, S., Depta, G., Nasti, R., Verotta, L., Zaccheria, F., Ravasio, N.: MakeUp Technology (2) (2020). https://www.ceceditore.com/ makeup-technology-autunno-inverno-2020/\#fb0=1

Publisher's Note Springer Nature remains neutral with regard to jurisdictional claims in published maps and institutional affiliations. 